\title{
Theories on Otic Symptoms in Temporomandibular Disorders: Past and Present
}

\author{
Teorías de los Síntomas Óticos en los Trastornos Temporomandibulares: Pasado y Presente \\ "Luis Miguel Ramirez Aristeguieta; **Germán Pablo Sandoval Ortiz \& ****Ballesteros, L. E.
}

RAMIREZ, A. L. M.; SANDOVAL, O. G. P. \& BALLESTEROS, L. E. Theories on otic symtoms in TMD: Past and present. Int. J. Morphol., 23(2):141-156, 2005.

SUMMARY: For many years otic symptoms have been closely observed in TMD clinical practice. This review includes trials that meet eligibility criteria in the field of otic symptoms diagnosed and treated by a stomatognathic focal point. The aim is centered on the implications of the debated cause-effect connection between otic symptoms and TMD offering a probable bond between the TMJ, ear and adjacent structures. The rationalization is based on an embryological and anatomical approach that offers explanations on the otic pathogenic mechanisms symptoms interconnected with TMD. The accompanying reciprocity among disciplines of odontology and otolaryngology is brought together by TMD and otic referred mutual symptomatology as is showed in multiple trials. This research is an attempt that targets the integration of these two health specialties in the diagnosis and treatment of this type of population.

KEY WORDS: Tinnitus; Otic fullness; Vertigo; Temporomandibular Disorders; Referred Pain.

\section{INTRODUCTION}

Temporomandibular disorders (TMD) are a subclassification of musculoskeletal disorders and include a wide range of orofacial conditions with multiple etiologies that mask a great variety of subjective signs and symptoms. These can be referred isolated or combined from the temporomandibular joint (TMJ), the masticatory muscles, the cervical muscles and associated structures. TMD and its referred symptomatology in their acute-chronic condition can seriously affect quality of life. The causal relationship between heterotopic pain and the masticatory system is found in large numbers of adult patients as well as in the infant population. These symptoms appear similarly in adults as in children, (Youniss, 1991; Lipton et al., 1993; Skeppar \& Nilner, 1993; McNeill, 1997) but the prevalence of TMD pain can range between 1.5 to 2 times higher in women than in men. (Solberg et al., 1979; Klausner, 1994; Dao \& LeResche, 2000; Lund et al., 2001).

TMD usually manifests itself as symptoms in the head and neck, occurring as articular, facial, otic and craniosinusal pain as well as cephalalgic symptoms. These symptoms are also associated with shoulder and back pain, (Bernstein $e t$ al., 1969; Hellstrom et al., 2000) which can generate referred orofacial symptomatology by involving the anterior, lateral and suboccipital cervical muscles in maximum occlusion. (Curtis, 1980; Edmeads, 1988; Cooper \& Cooper, 1993; Mense, 1993; Santander et al., 1994; Keersmaekers et al., 1996; Dos Reis et al., 2000).

There appears to be a cause and effect relationship between orofacial disorders and dysfunctional masticatory activities such as bruxism and emotional disorders. (Greene \& Marbach (1982); Greene \& Laskin, 2000). Therefore bruxism (microtrauma resulting from a subconscious non-functional clenching and grinding of the teeth) (Kato et al., 2001) plays a meaningful role in TMD and referred orofacial symptoms although many researchers consider the involvement of bruxism and TMD inconclusive. (Pergamalian et al., 2003).

\footnotetext{
Doctor of Odontology with a degree in Prosthetic Dentistry and Temporomandibular Disorders. Professor of Morphology in the Department of Basic Sciences of the Medicine Faculty - Universidad Industrial de Santander (UIS) - Bucaramanga - Colombia.

** Medical Doctor with degree in Otolaryngology. Otolaryngology and Chief Surgeon of Head and Neck Surgery Department in Carlos Ardila Lule Clinic - Bucaramanga - Colombia. Surgery Professor of the Medicine Faculty - Universidad Industrial de Santander (UIS) - Bucaramanga - Colombia. Centro Médico Carlos Ardila Lule, Bucaramanga- Colombia.

**** Medical Doctor with Degree in Anatomy. Basic Sciences Department Director, Professor of Morphology in the Department of Basic Sciences of the Medicine Faculty - Universidad Industrial de Santander (UIS) - Bucaramanga - Colombia.
} 
Although people with TMD suffer local orofacial muscle pain that affects the muscles, they can also suffer referred pain that can affect the cervical and the middle ear muscles with varied symptomatology that ranges from otic symptoms to headache and neck pain. These symptoms can be associated with TMD from muscle hyperactivity that produces primary and referred pain symptomatology and an otic non-painful expression. (Gelb \& Arnold, 1959; Okeson, 1998). It is important to know that symptoms of the ear are not present in over $50 \%$ of the patients who express otic complaints such as retroauricular and/or preauricular pain, tinnitus, vertigo, hearing impairment, otic fullness, and ear popping sensations. (Gelb et al., 1959; Gelb \& Tarte, 1975; Kuttila et al., 1999; Kuttila et al., 2001). Bernhardt et al., (2004) found a significant correlation between tinnitus and TMD, affirming that TMD might cause otologic symptoms.

Monson and Wright in 1920 related the position of the jaw and the TMJ to impairment of hearing in child and adult populations. Decker in 1925 and Goodfriend in 1933 related otic symptoms with TMJ. (Decker, 1925; Parker \& Chole, 1995. Costen (1934) associated auricular and craniosinusal symptoms with articular disorders called Costen's Syndrome. Costen was the first one to describe otic symptoms in total or partial edentulous patients and the reflex muscular contraction (Shapiro \& Truex, 1943) of muscles innervated by the mandibular branch of the trigeminal nerve (V3). Most of the populations are not aware of the relationship existing between symptoms such as headache and otalgia to TMD and the masticatory system. It can be observed in the clinic how functional and inflammatory disorders of TMJ in their acute state are recognized by patients as "ear pain". (Rubinstein et al., 1990; Ash \& Pinto, 1991).

\section{Prevalence and evidence}

Patients with otologic symptoms usually have more painful orofacial muscles than in people without otic symptoms. The otic pain in individuals with TMD without a pathological condition in hearing or in the nasopharinx can be explained as a referred pain from the masticatory muscles, TMJ and associated structures. (Miller \& Wyrwa, 1992).

There appears to be a connection between otic symptoms and the muscular and articular dysfunction in the head and neck. (Koskinen, et al., 1980) Chart 1 widely demonstrates how otic symptoms are intimately associated with TMD. (Goodfriend, 1933; Principato \& Barwell, 1978; Brookes et al., 1980; Gelb \& Bernstein, 1983a,b; Fricton et al., 1985; Bush, 1986; Wedel \& Carlsson, 1986; Chole \& Parker, 1992; Kisnisci, 1999; Wright \& Syms, 2000; Tuz et al., 2003). It is important to mention that in this chart the researchers at the beginning of this century recognized TMD patients based on the clinician's preferred etiology hypothesis but the multifactorial nature of TMD began to be acknowledged in 1960 due to a demand for its diagnostic criteria. Between 1990 and 1996 TMD diagnostic criteria has reached a consensus. ( Dworkin \& LeResche, 1992; McNeill, 1990, 1993; Sessle et al., 1995; Okeson, 1996 and National Institute of Health Technology Assessment Conference on Management of Temporomandibular Disorders).

It is still a mystery the unique cause of otic symptoms. Among a several suggested origins that include Meniere's disease, acoustic neuroma, ear trauma, noise exposure, otosclerosis, ototoxic drugs and presbycusis, TMD appear to play a relevant role. This factor could generate some conflict because the wide range of other causes that may express otic symptoms, cases that are frequently observed in the otolaryngology daily practice. For example Tinnitus and vertigo, as well as other otic symptoms, have been implicated in patients with a compromised systemic condition like systolic and diastolic pressure levels but with no correlation demonstrated (Weiss, 1972; Chatellier, et al., 1982).

The prevalence of dizziness in patients with TMD ranges from $40 \%$ to $70 \%$ and that of vertigo from $5 \%$ to $40 \%$. (Cooper et al., 1986). In relation to tinnitus, it is not clear yet if TMD contributes to its development or if they are the same phenomenon. (Bush, 1987). Lockwood et al., (1998) found up to 75\% of patients had alternate intensity of tinnitus with voluntary muscular orofacial movement. Vergara (1996) also found a solid relationship between facial and masticatory muscle movements and the variations in the intensity of tinnitus. (Yamamoto et al., 1985). Morgan (1992) finds that when the muscles of patients with otic symptoms are palpated $75 \%$ have trigger points. Rubinstein \& Carlsson, 1987) reasoned that tinnitus is not a disease but a symptom in the otologic spectrum. Rubinstein found patients with chronic tinnitus responding less to stomatognathic treatment than those with acute tinnitus. Vernon et al. (1992) expressed that in tinnitus the greater the quantity of different sounds then the more complex the tinnitus and TMD. Lam et al. (2001) noted that the prevalence of referred otic pain and other otic symptoms of non otologic origin in patients with TMD vary from $3.5 \%$ to $42 \%$ and that the prevalence of tinnitus in patients with TMD seems to be higher than that found in the general population. The frequency of tinnitus in patients with TMD varies from $33 \%$ to $76 \%$. Rubinstein, 1993. Hazell (1981) reported that 39\% of the patients with tinnitus showed frequent tension headaches with fatigue and muscle soreness in facial and masticatory muscles. Bjorne et al. (Bjorne \& Agerberg, 1996; 
Bjorne et al., 1998) expressed that the hearing damage and auditive loss frequently associated with tinnitus is strongly related to emotional tension such as headaches, cervical and pericranial muscular tension, as well as dreaming disorders that produce suboccipital muscular tension and vertigo experience.

\section{Rationalized appoach to pathogenic mechanisms:}

Several authors have tried to find an explanation between otic symptoms and TMD with some interesting answers. How TMD affects otic health may sound illogical to some clinical researchers but must be understood and observed in an anatomic-embryologic-physiologic form to elucidate more than a few possibilities in its potential connection.

\section{Embryology link}

Focusing on the articulation and the masticatory muscles as a potential origin of some otic effects it is undeniable that this common embryologic beginning of both the ear and TMJ at least proclaims them as next door neighbors.

In humans the development of TMJ and structures such as the pharynges, the pharyngotympanic tube, and the tympanic cavity is complex and still a controversial subject. Meckel's cartilage, which is the first branchial arch, forms the jaw and the maxillar. The first and second arches form the ossicle chain. In this chain the malleus has a double origin: the anterior process originates from mesenchimal cells (os goniale) through intramembranous ossification, and the rest from Meckel's cartilage, through endochondral ossification. (Rodríguez et al., 1991, 1993; Whyte et al., 2002). The middle auricular bones relate the malleus (hammer), to the condylar blastema and the temporal blastema by fibrous connections passing through the petrotympanic fissure that Rees (Rees, 1954) named the discomalleolar ligament. These fibrous connections of the lateral pterygoid muscle in the Meckel's Cartilage form the interarticular disc by mechanical stimulation of this muscle although there isn't total agreement (Yuodelis, 1966). A neurological, vascular and ligament connections between the TMJ and the middle ear persist in the course of articulation development because of the continuity in the Meckel's Cartilage through the petrotympanic fissure that in adults shows an incomplete closing. The medial pterygoid muscle and the tensor tympani muscle develop from the temporal blastema. These structures along with the tensor veli palatini are innervated by V3 through the otic ganglion, which innervates the masticatory muscles coming from the mesoderm of the first branchial arch. (Baume, 1962; Furstman, 1963; Misurya, 1976;
Thilander et al., 1976; Wong et al., 1985; Ohta et al., 1993; Perry et al., ; Sadler, 1998; Schames et al., 2002). Myrhaug (1964) reasoned that the ossicular chain and the middle ear muscles belong embryologically to the chewing system and that after this they become and serve as the hearing sense.

\section{Muscular involvement}

The muscles tensor tympani and tensor veli palatini are the first focus of the functional origin of the otic disorders with symptoms like tinnitus, otic fullness, subjective hearing loss and vertigo. The center of attention of their involvement starts when it is understood that anatomically they are muscles of the middle ear although they are really muscles of mastication because they are modulated by motoneurons coming form the trigeminal motor nucleus (V3). (Campbell et al., 1982; Myrhaug; Eckerdal, 1991; Ciancaglini et al., 1994; Greene, 2001; Travell \& Simons, 2002) TMD high muscular activity can be exacerbated originating in this nucleus with its possible otic consequences from the tensor tympani and tensor veli palatine muscles participation.

These complex neuromuscular interactions between the masticatory muscles and the ear were named "Otognatic Syndrome" by Myrhaug in 1964 and then "Otomandibular Syndrome" by Bernstein in 1969 and Arlen in 1977. The patients with otomandibular syndrome have one or more otic symptoms without having a real source in the ear, nose or throat but with one or more mastication muscles in a state of constant spasm.

The stapedial muscles accompany the tensor tympani muscle in the middle ear mechanism. The contraction of the stapedial and tensor tympani muscle is produced during high sounds and immediately before speaking. (Klockhoff \& Anderson, 1960). These muscles are involved in the "centrifuge auditory inhibition" control from the Central Nervous System (CNS) that protects and filter the auditory afferent conduction to the CNS by the contraction of these muscles. The stapedial muscle improves external vocalization reducing the masking effect of autogenous sounds. The tensor tympani responds to strong external stimuli and is activated by vocalization, chewing, swallowing and movement of the facial muscles. (Kamerer, 1978; Gray, 1983). It is imperative to recognize that the ossicular chain in the middle ear is practically sustained in a fragile way by the tympanic membrane, some ligaments of the malleus and incus and the tendons of the stapedial and tensor tympani muscles. These structures sustain the bones of the middle ear in an efficient biomechanical function on the acoustic stimulus movement. Myrhaug noted that the equilibrium of the ossicular chain depends on the tonic state of tensor tympani and stapedial muscle (opposing muscles) regulating 
the normal functioning of the structures that lead sound into the middle ear. In TMD the sustained contraction of tensor tympani muscle can alter the ossicular spatial position and the endolymphatic pressure through the transmitted changes from the oval window to the labyrinth walls. This can unchain and unbalance the vestibular impulses expressed in vertigo. Additionally, the same middle ear pathogenic muscle mechanism can diminish the sonic transmitting vibration from the tympanic membrane toward the oval window through the ossicular chain which is expressed as a hearing impairment. Ogutcen-Toller \& Juniper (1993) suggested that the structures that lead to sound in the middle ear could be affected by the contraction of the tensor tympani muscle produced by TMD. Considering that TMD can produce an episodic or constant muscle contraction or spasm depending on its stage, the otic symptoms appear as an episodic or constant presence.

The dysfunction of the tensor tympani muscle in conjunction with tensor veli palatini muscle also plays an important role in the relationship of TMD and otic symptoms. Neuromuscular dysfunctions of these muscles may trigger alterations in the sound-conducting apparatus. TMD produces contraction and tension in the tensor veli palatini and tensor tympani muscles that can generate different abnormal muscular behaviors: in subjective tinnitus there is a contraction of the tensor tympani muscle and in objective tinnitus where there is a rhythmical opening and closing of the pharyngeal area of the pharyngotympanic (palatal myoclonus), the contraction is present in the tensor tympani and tensor veli palatini muscles. (Virtanen, 1983). Zipfel et al. (2000) noted that the most common mechanical origin of objective tinnitus is palatal myoclonus and middle ear myoclonus (rhythmic movement of the tympanic membrane secondary to repetitive contraction of the tensor tympani and stapedial muscles).

The normal function of the pharyngotympanic tube is to equalize the pressure of the middle ear and it is regulated by the tensor veli palatini muscle. The pharyngotympanic tube communicates with the middle ear to the nasopharinge by contracting the tensor veli palatini muscle assisted by the levator palatini muscle during velopharingeal movements such as swallowing and the inhaling phase of respiration. (Misurya, 1976; Swarts, 1990; Spauwen et al., 1991; Su et al., 1993; Ishijima et al., 2002). Movement patterns such as yawning, laughing, swallowing and coughing involve pharyngeal and laryngeal muscles that activate the tensor tympani. Salen \& Zakrisson (1978) found that pharyngeal and laryngeal muscles work simultaneously during swallowing with the tensor tympani and assist in Eustachian tube ventilation similar to an air pump. During its reciprocal contraction generates an inner deflection of the tympanic membrane that breaks the seal of the mucosal membranes of the pharyngotympanic tube isthmus that expels air and contributes to the ventilation of the middle ear. The alteration of its function can changes the intratympanic pressure and can generate tinnitus, vertigo, sensations of hearing loss of low tones, otic fullness. Its dysfunction can also produce otitis media with effusion, especially in children. (Alper et al., 1997). Marasa \& Ham (1988) as well as Youniss think the pharyngotympanic tube dysfunction plays an important role in otitis media with effusion. Children are more susceptible to chronic otitis media with effusion especially during respiratory system infections because their pharyngotympanic tubes are configured as a short, horizontal and wide lumen. (Holborow, 1975).

Costen noted an interesting explanation why the Eustachian tube dysfunction would occur by neighboring compression. The compression comes about because of the relaxation of the upper head of the lateral pterygoid and medial pterygoid muscles that occurs in a loss of vertical dimension from edentulism. (Dolowitz et al., 1964). McDonnell et al. ( 2001) express in the same vertical scenario that children with deep dental overbites were 2.8 times more increased risk for developing pharyngotympanic tube dysfunction than those without deep bites. The result of this is the compression and bunching of the muscular mass (tensor veli palatini) and associated structures in repose (muscular hypotension) by lateral pterygoid and medial pterygoid muscles. Normally the pharyngotympanic tube is maintained closed by the collapsing pressure of an external mass. The pharyngotympanic tube maintains a closed position at rest, which protects the middle ear from retrograde flow of nasopharynx microflora during rapid fluctuations in nasopharyngeal pressure associated with breathing, swallowing, coughing, sneezing, and nose blowing. Under normal conditions the contraction of the tensor veli palatini muscle opens the lumen of the pharyngotympanic tube while it presses laterally on the medial pterygoid muscle. (Leuwer et al., 2002). Kelly \& Goodfriend (1964) found a possible union between vertigo, nausea, vomit and syncope in 105 patients with over-closed dental relations because the medial pterygoid muscle enlarges and compresses, and he found the complete resolution of their symptomatology in $89 \%$ of these patients by increasing their vertical dimension. Another picture with the same medial pterygoid muscle and pharyngotympanic tube proximity is the hypertonicity and spastic contraction of medial pterygoid muscle due to muscular dysfunction in TMD. Also, this could externally compress the tensor veli palatini muscle and generate anatomical interferences with the normal function of the pharyngotympanic tube. In this scenario the contraction of the tensor veli palatini muscle can be interrupted and causes difficulty in its opening. (Ross, 1971). If the mastication 
muscles are hypertonic because of TMD it is also possible that the tensor veli palatini and tensor tympani muscles can be hypertonic because of the common innervation by V3. As the tensor veli palatini remains spastic its normal function of opening and closing the pharyngotympanic tube will cease generating otic fullness among other otic symptoms.

At this point, the complexity of the middle ear pressure aeration mechanisms can be observed. If the tensor tympani and tensor veli palatine muscle dysfunction can generate otic symptoms each one separately, then the effects of an agonist co-working are anatomically more problematic. Barsoumian, Kuehn et al. (1998) corroborate Lupin's 1969 findings and those later of Rood \& Doyle (1978) findings by discovering in adult cadavers how the fibers of the most external zone of the tensor veli palatini muscle and the fibers of the tensor tympani are joined in the middle ear. (Rood, 1973; Williams et al., 1989; Prades et al., 1998). Kierner et al. (2002) also found this functional connection between the tensor veli palatini and the tensor tympani muscles in human cadavers by histological analysis. (Proctor, 1967). Because of this, the tensor veli palatini has an additional bone origin in the manubrium of the malleus. Consequently these muscles act synergistically together and temporary can increase intratympanic pulling force with otic symptoms like otalgia, tinnitus, vertigo and subjective hearing loss. The dysfunction of them in TMD can either individually or in combination modify the medial position of the malleus and the tympanic membrane since the spatial disposition of the ossicular chain can be modified by muscle force. Schames et al. found a possible myofibrotic contraction of the tensor tympani and tensor veli palatini muscles due to dysfunction generated by TMD. This complicates this anatomical and functional relationship as a consequence of reduced muscle fiber length.

\section{TMJ and middle ear adjoining}

Dissections of human adults and fetuses carried out by Pinto (1962) Komori et al. (1986) and other researchers (Rees, 1954; Coleman, 1970; Ioannides \& Hoogland, 1983; Perry et al., 1985; Loughner et al., 1989; Rodríguez \& Vásquez, et al., 1993; Morgan et al., 1995; Mérida-Velasco et al., 1997; Rodríguez-Velásquez, et al., 1998) proved a specific anatomical link between the TMJ, the mandibular body and the middle ear. This connection is made by the discomalleolar and the anterior malleolar ligaments that attach to the malleus of the ossicular chain in its anterior process and create a biomechanical connection between the middle ear and the mandibule. (Hoshino, 1988).

The anterior malleolar ligament is a continuation of the sphenomandibular (tympano-mandibular) ligament noted by Burch (1966) and according to Komori et al. and
Ogutcen-Toller (1995) inserts on the ventral surface of the malleus coming out to form a horizontal "V" with the discomalleolar ligament in the petrotympanic fissure. According to Pinto, the discomalleolar ligament is found more external and is inserted in the medio-posterior-superior border of the capsular ligament and the disc. According to Komori et al. it is inserted only in the medio-posteriorsuperior zone of the retrodiscal area and in the articular capsule. The anterior malleolar ligament is more medial than the discomalleolar ligament and connects the sphenomandibular ligament along with the Chorda Tympani nerve (VII) in the petrotympanic fissure (Iter Chorda Anterius) trespassing together within the Huguier Channel. The sphenomandibular ligament is inserted in the lingula or mandibular spix spine and originates in the malleus, part of the sphenoid spine and the most medial zone of the petrotympanic fissure. (Rodríguez et al., 1992) The malleolar anterior ligament is an embryological remainder of the Meckel's cartilage and the disc-malleolar ligament is a remainder of the lateral pterygoid muscle.

These structures can be stretched in a TMJ functional or inflammatory disorder affecting the middle ear structures in some patients. The otic symptomatology in this scenario can be expressed as tinnitus, vertigo and otalgia. The first two symptoms start in the altered position of the stape because the force applied to the middle ear bones by these ligaments. Otalgia can be present by peripheral nerve stimulation in the tympanic membrane due to the traction of the malleus that is bonded to the membrane. Ren \& Isberg (1995) found a significant correlation between internal derangement of the TMJ and tinnitus. In their research disk displacement was found to be present in the ipsilateral joint in all 53 patients who had unilateral tinnitus. In 1933 Bernstein et al. observed how in extreme jaw movements some patients could change the intensity and quality of tinnitus. According to Eckerdal, the range of movement of these ligaments depends on the fibrous connection on the walls of the petrotympanic fissure, corroborating Coleman's findings in 1970.

How these ligaments can start a force in the middle ear bones is the question. This ligament link between the TMJ and the middle ear can be biomechanically subjected to functional or inflammatory articular disorders since the luxation or displacement of the disc and the secondary edema from inflammation (Sessle et al.,; Myers, 1988; Johansson et al., 1990) can produce anterior tension on the discomalleolar ligament because of the disc disposition and the additional increase of intrarticular pressure by the edema. The sphenomandibular and malleolar anterior ligaments only can be tensed in a position of marked over-closure also stretching the ossicular position, explaining the increase of 
tinnitus in exaggerated intermaxilar positions. (Bernstein $e t$ al., 1969; Myers, 1988; Rubinstein et al., 1990). Bernstein, observed how in extreme jaw movements some patients could change the intensity and quality of tinnitus. Loughner et al. (1989) reasoned that in surgeries for TMJ where condyle is distracted the ossicular chain could be injured by the extreme traction of these ligaments over the anterior process of the malleus. Additionally in relation to the TMJ-Middle ear bone communication (Huguier Channel) Marasa \& Ham suggested that the inflammation produced by inflammatory disorders of TMJ can spread through the petrotympanic fissure to the middle ear and generate otitis media. The osseous communication between the middle ear and TMJ is capable subsequently to start pathologies with doubtful origins like a TMJ septic arthritis with an occult original infectious site, but in presence of infectious otitis media. (Leighty et al., 1993; Regev et al., 2003). Using the same bone connection, the edema produced by inflammatory or functional disorders from the TMJ can spread through the petrotympanic fissure to the middle ear a fluid collection and generate vulnerable infection (otitis media) via this route. (Marasa \& Ham, 1988; Moses et al., 1998).

In a similar way the proximity of TMJ and the middle ear can be explored in a vascular and lymphatic point of view. These components go through the petrotympanic fissure in the same form like the ligaments explained above. Merida-Velasco et al. (Mérida- Velasco et al., 1999) confirmed Bleicker's findings that in newborns the small vessels of the anterior portion of the middle ear cross the petrotympanic fissure and reach the venous retrodiscal plexus that drains into the retromandibular vein, which is a part of the articular vascular plexus. In adults the most medial branches of the posterior group of the tympanic anterior artery (behind TMJ) irrigate the tympanic cavity and the external auditory meatus. The most medial branches are in intimate contact with the discomalleolar ligament that enters the middle ear through the petrotympanic fissure and with the external ear through the most external branches in the scamotympanic fissure. This vascular relationship between TMJ and the middle ear can explain the referred otic symptoms in presence of secondary vascular reflex from TMJ disorders. (Williamson, 1990). Gelb et al. (1997), in relation to the labyrinth lymphatic drainage mechanisms and based on Young (1952) discoveries, suggested that the mechanical obstruction of the pharyngotympanic tube by TMJ inflammation or muscular cause could involve the lymphatic channels coming from the labyrinth to the middle ear and the retro-naso-pharyngeal lymph nodes which can diminish the outflow of perilymph. This increases the volume and pressure of the labyrinthine fluid and "hydrops of the inner ear" and consequently expressing an otic symptomatology. In the same way functional or inflammatory disorders of TMJ could exert pressure on the lymphatic contents coming from the middle ear through the petrotympanic fissure.

As can be seen, the TMJ is a small compacted structure with vascular and neurological tight components that can easily be injured during TMJ disorders. Ash \& Pinto reasoned how the otic symptomatology can be generated by injury of the parasympathetic nerve fibers of the auriculotemporal nerve that travel from the otic ganglion and tympanic plexus (glosopharyngeal nerve). When irritated can produce a reflex vascular spasm in the labyrinthine system secondary to abnormal stimulation of these fibers. (Kopp, 2001). The irritated auriculotemporal nerve can produce otalgia because it profusely innervates articulation as well as the tympanic membrane, the anterosuperior zone of the external ear, the tragus and the external part of the ear among other structures that can explain the auricular pain experienced. (Fernández et al., 2003 and Schmidt et al., 1998). Johansson explained that in the nerve entrapment etiology (auriculotemporal nerve) is important not only to anatomical mobility and bone deformities but also inflammation of vascular and muscular structures that can injure closely situated nerves since inflammation can alter and reduce the normal contour and size of the anatomical passages. Loughner et al. (1990) confirmed that during lateral pterygoid spasm and hypertrophy, it can injure auriculotemporal nerve

Finally Myers in 1988, found that TMJ inflammation disorders produce a pattern of edema leakage and fibrosis, subsequently, that extends into neighboring areas following the patterns of least resistance through the muscular masses in medial and anterior-medial areas of TMJ. This inflammatory course can compress nerves: alveolar, lingual and chord tympani. Nerve entrapment origin is important not only because of the anatomical mobility and bone deformities but also inflammation of vascular and muscular structures that can injure nerves in close proximity since inflammation can alter and reduce the normal contour and size of the anatomical passages. The fibrosis and adhesions in progress by this inflammation leakage can produce tension in the carotid sheath during jaw and neck movements. This tension is transmitted to the jugular foramen and to the endolymphatic sack, generating pressure over the hair cells of the cochlea producing tinnitus and vertigo. Another pattern of outflow is described which passes between the origin of the levator palatini muscle and the tensor veli palatini muscle toward the most vulnerable area of the Eustachian tube (isthmus). This pressure can generate otic fullness sensation. Myers demonstrates the fragility of the extrabony extensions of the middle ear in the Eustachian Tube and of the internal ear in the endolymphatic sack. 


\section{Peripheral and Central Nervous System contribution}

Otalgia can be expressed like referred (heterotopic) pain with an orofacial origin that is different to the ear. Miller \& Wyrwa (1992) suggested that in the "Theory of Convergence" by Sessle, (Sessle, 2000) the pain referred to the ear (which is secondary to orofacial soreness (Svensson \& Graven-Nielsen, 2001) and chronic painful stimulus) begins by chronic irritation of the Peripheral Nervous System (PNS) which alters the normal physiologic functioning of the brain and sensitizes the CNS. These nerves send peripheral nociceptive impulses to second-order neurons through the trigeminal subnucleus caudalis. The sensorial innervation of the ear and periauricular region is derived form cranial nerves V, VII, IX, X, C2, and C3. The neurons of the spinal nucleus of the trigeminal nerve in the brain stem particularly in the subnucleus caudalis and the transition zone between caudal and interpolar subnucleous, receive these orofacial and neck afferents (nociceptive) signals. The central sensitization also involves spinal motor neurons, the thalamus and the somatosensorial cortex, which makes a facilitator effect on referred pain and muscle reflex spasms. The "convergence" of these afferent nerves toward the spinal nucleus of the trigeminal, the thalamus and the cortex can confuse the brain as to the location of the sources of peripheral chronic pain by the sensitization of afferent interneurons not related.

Okeson (1998) noted an accumulation of neurotransmitter substance in the interneuronal synapses when pain stimulus is continuous leading to the leakage of neurotransmitter toward groups of adjacent interneurons. The adjacent interneurons are modulated by the action of these neurotransmitters, generating the perception that these impulses are coming from the same pain area. This explains how the originally excited neuron transmits information about the real origin of pain (primary pain) and the other excited neurons show central excitement which means that the perceived pain from these neurons is heterotopic pain, i.e. referred pain.

Woolf \& Thompson (1991) reasoned that the pathogenicity of pain is in part a reflex of the CNS neurons capacity to suffer dynamic alterations in the properties of response and that the nociceptive fibers can trigger this functional plasticity. Chronic pain brings about, as a consequence, a reduction in the threshold of the cutaneus afferent ways and an expansion of the peripheral response. The repeated peripheral stimuli of primary afferent fibers produces a progressive increase in the action potential discharged and in this same manner a prolonged enlargement in the excitability of spine and brain stem neurons posterior to deep and chronic pain stimulus. Coderre et al. (1993) found that it is possible that the normal pain inhibition process (Wall, 1978) in the brain stem is altered by peripheral pain reception and that the central sensitization process generates expansion of the perceived peripheral pain.

Taking into account the "Pain Adaptation Model," by Lund et al. (1991) and how the chronic musculoskeletal pain present in TMD produces a protective adaptation to avoid further muscular pain, then it can be expected that this mechanism perpetuate the muscle fatigue cycle dysfunction because the larger muscle agonist-antagonist contractions which generate more chronic pain and continues to sensitize the peripheral orofacial receptors. These receptors become involved in the pathophysiology of the central excitatory effect by constant afferent muscle stimulation continuing the recurrent TMD cycle. (Hu et al., 1992, 1993; Svensson et al., 1996, 1998).

The orofacial pain can express its constant input to the CNS in a systemic way. The motor nucleous of various cranial nerves like the facial (VII), glossopharyngeal (IX), vagus (X), and the hypoglossal (XII) including the trigeminal (V) are stimulated by the ventral trigemino-thalamus tract carrying to the cortex nociceptive and sensorial signals in an ascending "divergent" manner coming from the contralateral spinal and principal sensory trigeminal nucleous. (Affifi \& Bergman). The importance of this resides on the provoked neural "abnormal muscular reflex behaviors" influenced by chronic muscular-articular-mucosal deep pain toward all the skeletal muscles innervated by this pathway: tongue, intrinsic and extrinsic larynx, pharynx and palatal, tensor and levator veli palatini, some of the styloid process, facial, stapedius (possible stapedial intratimpanic mioclonus), tensor tympani, digastrics, mylohyoid and all the agonist muscles of mastication. It will be interesting to determine the coverage of the collateral branch stimulation of the trigemino-thalamus tract on the vital centers (respiratory, metabolic and cardiovascular) and secretomotor activity of the motor nucleus of the X, IX and VII cranial nerves in deep and chronic pain situation.

Symptoms like vertigo, tinnitus and subjective hearing loss can result from a new auditory innervation pattern that involves the trigeminal nerve. Vass et al. (1998). found that in animals the trigeminal innervation of the vascular system controls the cochlear and the vestibular labyrinth function. The projection of the ophthalmic fibers of the trigeminal Gasser ganglion to the cochlea through the basilar and anterior inferior cerebellar arteries can play an important role in the vascular tone in quick vasodilatatory responses to metabolic stresses like intense noise. The inner ear disease which produces otic symptoms such as sudden hearing loss, vertigo and tinnitus, can originate from the 
reduction of cochlear blood flow due to the presence of abnormal activity in the trigeminal ganglion in patients with herpes zoster, migraine or by the central excitatory effect origininated in a chronic or deep pain produced by TMD. Vass et al. also found that the trigeminal sensorial innervation plays an important role in the regulation and balance of the cochlear vascular tone and in the vestibular labyrinth channel that can be responsible for the symptomatic complexity of some cochlear diseases related to inner ear blood flow. Furthermore the headaches, tinnitus, hearing loss, vertigo and Meniere's syndrome can be explained by this innervation model. A parallel discovery by Shore et al. (2000) found that the trigeminal ganglion innervates the ventral cochlear nucleus and the superior olivary complex. This can interfere with the auditory pathways which lead to the auditory cortex in the presence of constant peripheral somatic signals from the ophthalmic and mandibular trigeminal peripheral innervation in TMD. Levine (1999) suggests a similar somatic interference or inhibition of the auditory perception in the dorsal and ventral cochlear nucleus. Young et al., 1995). suggests that this stimulus is so strong that it can interfere with moderate-level acoustic stimuli. The perception originates from spinal and cranial nerves impulses in the medullary somatosensory nucleus and is modulated by muscle fatigue in the head and neck areas. These CNS interactions between the somatosensory system and the auditory system (including the extralemniscal auditory pathway (Moller et al., 1992) can explain the origin of otic symptoms without existing disease in the ear, nose or throat. (Sobhy et al., 2004).

Forceful muscle contraction in TMD can elicit modulations in the neurological auditory perception and body balance. Bjorne et al. $(1996,1998)$ describe a type of vertigo and tinnitus without a cochlear and labyrinth origin. They found that these symptoms can be initiated in the facial and cervical muscular dysfunction in TMD which generates hypertonicity and muscular spasm irritating nerves and blood vessels by muscular trapping. When this compression develops in the neck, it distorts the normal propioceptive reception to the vestibular nucleus in the oculo-vestibular muscle reflex that controls the postural position of the head. (Cowin \& Bryner, 2002). The cervical muscular compression could generate tension on the vertebral artery which feeds the basilar artery and the inner ear inflow. Bjorne suggested that this tension can produce temporary or permanent hearing loss. They reasoned that constant muscular tension is associated with tinnitus and vertigo by neuroplasticity originating in the irritation and posterior peripheral sensitization. (Bjorne \& Agerberg, 2003; Salvinelli, et al., 2003).

Tinnitus can result from the interaction between the somatic and otic nervous pathways inside the CNS without involving the peripheral structures (cochlea and choclear nerve). Levine suggested that the reduction in the auditorynerve input leads to desinhibition of the dorsal cochlear nucleus and an increase in spontaneous activity in the central auditory system which is experienced as tinnitus and can be modulated by somatosensory input. Lockwood et al. (2002) named this phenomenon "Cross-Modal Inhibition" and suggests that hearing loss leads to reorganization (neuroplasticity) of the pathways in the central auditory system and leads to abnormal interactions between auditory and other central pathways, showing similarities between neuropathic pain and tinnitus with a TMD origin.

\section{DISCUSSION}

The development of TMD is multifactorial and is centered in local, systemic and recent psychological factors. Predisposition, initiation and perpetuating factors increase the biomechanic and the neuromuscular aspect of the dysfunction. The psychological foundation in patients with acute and chronic TMD shows how anxiety, depression, and personality alterations add to the complexity of this disorder. Understanding these disorders is developed by fusing the traditional biomedic model with psychological, social and behavioral dimensions of the patients. (Mc Neill, 1997; Greene \& Lakin, 2000). An important and potent modulator of TMD are the emotional disorders. (Dworkin et al., 1987; 1987; Dworkin, 1994; Kinney et al., 1992; Gatchel et al., 1996; Molin, 1999). Treatment should emphasis physical management as well as behavior management in relation to this problem. This cascade of events that can start with emotional stress can be expressed in articular-muscular orofacial and cervical pain finally represented like otic symptoms.(Goodfriend, 1933; Myrhaug, 1964; Bernstein et al., 1969; Williamson, 1990; Kutilla et al., 1999) Meniere's syndrome or Endolymphatic Hydrops expressed like tinnitus, vertigo, hearing loss and otic fullnes could be explained partially or totally by this research that open a possibility in the therapeutics of this disease. (Myrhaug, 1964; Myers, 1988; Hu et al., 1993; Bjorne \& Agerberg, 1996). In orofacial pain the medical team rarely has interest in the muscular or articular orofacial evaluation and its crucial connection with referred cranial symptoms expressed. Otolaryngology and odontological exams are vital to establish differential diagnosis of the orofacial symptoms by TMD. These should incorporate both intraoral and extraoral muscle explorations of the head and neck (Kim et al., 1995) as well as palpation of the muscles and TMJ. (Conti et al., 2002). Also, a physical and visual examination of associated structures such as the pterygoid hamulus of the soft palate, the stylohyoid complex, the temporalis tendon, the sphenopalatinum ganglion, 
Table I. Percent of TMD-otic symptoms in different populations

\begin{tabular}{|c|c|c|c|c|c|c|}
\hline Researchers & $\mathrm{N}^{\mathrm{o}}$ TMD Patients & $\%$ Otalgia & $\%$ Tinnitus & $\%$ Vertigo & $\%$ Hearing Loss & $\%$ Ear Fullness \\
\hline Goodfriend, 1933 & 91 & 3 & 14 & 5 & 26 & --- \\
\hline Costen, 1934 & 400 & 38 & 13 & 12 & 13 & 6 \\
\hline Gelb-Arnold, 1959 & 100 & 13 & 27 & 5 & --- & --- \\
\hline Kelly-Goodfriend, 1960 & 102 & --- & --- & 75.5 & --- & --- \\
\hline Kelly-Goodfriend, 1964 & 105 & 25 & 44 & 100 & 44 & 30.4 \\
\hline Myrhaug. 1964 & 1391 & 21 & 32 & 28 & 32 & --- \\
\hline Dolowitz et al., 1964 & 64 & 100 & 43 & 5 & 38 & 48 \\
\hline Gelb et al., 1967 & 742 & 36 & 40 & 20 & 15 & --- \\
\hline Bernstein et al., 1969 & 86 & 93 & 42 & 14 & 33 & 62 \\
\hline Sharav et al., 1978 & 42 & --- & --- & 23 & --- & --- \\
\hline Principato-Barwell, 1978 & 25 & 100 & 44 & 44 & --- & --- \\
\hline Koskinen et al., 1980 & 47 & 47 & 20 & 26 & 24 & 26 \\
\hline Brookes et al., 1980 & 45 & 82 & 76 & 33 & 80 & 62 \\
\hline Gelb-Bernstein, 1983a & 1142 & --- & 41.5 & 20.6 & 15.4 & --- \\
\hline Gelb-Bernstein, 1983b & 200 & --- & 36 & 40 & 24.5 & 48 \\
\hline Fricton et al., 1985 & 164 & 42 & 42 & 23 & 17.7 & --- \\
\hline Cooper et al., 1986 & 476 & 50 & 36 & 40 & 38 & --- \\
\hline Wedel-Carlsson, 1986 & 148 & --- & 14 & 15 & 14 & --- \\
\hline Bush, 1986 & 105 & 82 & 33 & --- & --- & --- \\
\hline Bush, 1987 & 35 & --- & 33 & --- & --- & --- \\
\hline Williams, 1990 & 25 & --- & --- & 44 & --- & --- \\
\hline Henderson et al., 1992 & 21 & 85.7 & 90.5 & 76.1 & 66.6 & 90.5 \\
\hline Chole-Parker, 1992 & 338 & 100 & 59 & 70 & --- & --- \\
\hline Cooper et al., 1993 & 996 & 63 & 63 & 41 & 25 & 30 \\
\hline Ogutcen-Toller et al., 1993 & 57 & 40 & 17 & 8.7 & 26 & 5 \\
\hline Ciancaglini et al., 1994 & 797 & 1.6 & 6.4 & 1.6 & 7.6 & --- \\
\hline Ren-Isberg, 1995 & 53 & 98.1 & 100 & 54.7 & --- & 92.5 \\
\hline Parker-Chole, 1995 & 338 & 100 & 59 & 70 & --- & --- \\
\hline Wright et al., 1997 & 93 & 38 & 38 & --- & --- & --- \\
\hline Kisnisci et al., 1999 & 152 & 66.7 & 55.5 & 55.5 & 27.8 & --- \\
\hline De Felicio et al., 1999 & 30 & 53.3 & 66.6 & 20 & 20 & 76.6 \\
\hline Kuttila et al., 1999 & 411 & $12-16$ & $12-17$ & --- & --- & $5-9$ \\
\hline Wright et al., 2000 & 15 & 15 & 14 & 11 & --- & --- \\
\hline D'Antonio et al., 2000 & 90 & 100 & 51.1 & 31.1 & --- & --- \\
\hline Bruto et al., 2000 & 40 & 75 & 17.5 & --- & 15 & 17.5 \\
\hline Lam et al., 2001 & 470 & 32 & 26 & 18 & 12 & --- \\
\hline Pascoal et al., 2001 & 126 & 50 & 50 & 34 & 10 & 52 \\
\hline Tuz et al., 2003 & 200 & 57.2 & 48.3 & 42.7 & 29.4 & --- \\
\hline De Felicio et al., 2004 & 27 & 59.2 & 74 & --- & --- & 74.1 \\
\hline Sobhy et al., 2004 & 30 & 56.7 & 20 & --- & --- & --- \\
\hline
\end{tabular}

paranasal sinuses, the stylomandibular ligament, the parotid gland and the dental structures as well as possible cervical lesions should be included. (Hertz, 1968; Kopstein, 1975; Correl et al., 1979; Shankland, 1987; Ernest et al., 1991; Raustia, 1993; Kunachak, 1995; Peterson et al., 1995; Koelbaek et al., 1999; Farella et al., 2002). These exams are necessary in order to make a certain exclusionary diagnostic approach because of the similarity of orofacial symptoms. The pain present in TMD is a subjective symptom which possesses a relevant diagnostic difficulty, especially under the absence of objective and unique signs which is why a differential diagnosis including the associated structures is imperative.
Solving these problems should be approached carefully and conservatively. Reversible therapies should be the first treatment elected. Appropriate handling of TMD should implement non-invasive therapies. Physical selfregulation can eliminate negative oral habits and maintain more relaxed muscles, avoiding the ischemia and accumulation of algesic intramuscular and articular substances. Patients must be dedicated to their physical treatment and the management of their harmful habits and behavior in relation to their TMD. Conscious lifestyle changes that eliminate the muscular hyperactivity must be implemented. Prevention or reduction of factors such as bruxism, muscle hyperactivity inflammation has vital 
importance in any therapeutic treatment that gives the body the opportunity to repair itself and adapt to positive habits. In our daily practice we can observe how this pattern of referred symptomatology continuously repeats and how ultraconservative and conservative treatments restore the original state of health. (McNeill, 1997; Clark et al., 1999; Lockwood et al., 2002).

The orofacial symptoms present in TMD are like a mystery where the symptoms characterize the clues and the current epidemiological information and a good clinical examination constitute the evidence of where it is collected and takes form. Sometimes it is necessary to be ready to renounce some of the procedures and theories accepted as paradigms in professional practice. Only the flexible use of refreshing new knowledge and adoption of a new direction will benefit our patients, and diminish any unavoidable uncertainty in our daily practice.
Although the cause-effect relationship of the referred symptoms has an alliance with TMD continuous learning is still necessary. Many of these rationalization theories are not possible to prove using measuring instruments, but in daily clinical practice they are constantly applied. Costen's 1934 positions are regularly applied and appear to be one of the correct visions of TMD and their connection with referred symptomatology. Even after 68 years these theories give the impression of being applicable in the explanation of some of the orofacial symptoms. The clinicians that lean on anatomical and physiological exploration in their daily practice have given form to each one of these theories. These focuses should be kept in mind as diagnostic tools as they are the understanding we must have about the possible pathogenic approach of these disorders in order for successful treatment. Now then, all this takes in account a deep position when we observe the wide groove that exists on this topic between health disciplines like dentistry and medicine.

RAMIREZ, A. L. M.; SANDOVAL, O. G. P. \& BALLESTEROS, L. E. Teorías de los síntomas óticos en los trastornos temporomandibulares: Pasado y presente. Int. J. Morphol., 23(2):141-156, 2005.

RESUMEN: Por muchos años, síntomas óticos observados en la práctica clínica se han relacionado estrechamente con trastornos temporomandibulares (TTM). Esta revisión incluye juicios que plantean criterios específicos en el campo de los síntomas óticos diagnosticados y tratados desde un punto vista estomatognático. El objetivo está centrado en las implicancias debatidas causa-efecto entre síntomas óticos y TTM estableciendo un probable vínculo entre la ATM, oído y estructuras adyacentes. La revisión está basada en una aproximación embriológica y anatómica que explica los mecanismos y síntomas de patogenia ótica interconectados con TTM. El acompañamiento recíproco entre disciplinas de odontología y otorrinolaringología estableció un equilibrio entre los TTM y la mutua sintomatología ótica remitida, como está mostrado en múltiples diagnósticos. Esta investigación constituye un intento de alcanzar una integración entre estas dos especialidades médicas en el diagnóstico y tratamiento de este tipo de patologías.

PALABRAS CLAVE: Tinitus; Oido; Vértigo; Trastornos Temporomandibulares; Dolor referido.

\section{REFERENCES}

Affifi, A. K. \& Bergman, R. A. Neuroanatomia functional. Texto y Atlas. McGraw-Hill Interamericana, p. 176.

Alper, C. M.; Tabari, R.; Seroky, J. T. \& Doyle, W. J. Magnetic resonance imaging of the development of otitis media with effusion caused by functional obstruction of the eustachian tube. Ann. Otol. Rhinol. Laryngol., 106(5):422-31, 1997.

Arlen, H. The otomandibular syndrome: A new concept. Ear Nose Throat. J., 56(2):60-2, 1977.

Ash, C. M. \& Pinto, O. F. The TMJ and the middle ear: Structural and functional correlates for otic symptoms associated with temporomandibular joint dysfunction. Int. J. Prosthodont., 4(1):51-7, 1991.

Barsoumian, R.; Kuehn, D. P.; Moon, J. B. \& Canady, J. W. An anatomic study of the tensor veli palatini and dilatator tubae muscles in relation to eustachian tube and velar function. Cleft Palate Craniofac. J., 35(2):101-10, 1998.
Baume, L. J. Ontogenesis of the human temporomandibular joint: I. Development of the Condyles. J. Dent. Res., 41:1327-39, 1962.

Bernhardt, O.; Gesch, D.; Schwahn, C.; Bitter, K.; Mundt, T.; Mack, F.; Kocher, T.; Meyer, G.; Hensel, E. \& John, U. Signs of temporomandibular disorders in tinnitus patients and in a population-based group of volunteers: results of the Study of Health in Pomerania. J. Oral Rehabilitation, 31:311-9, 2004.

Bernstein, J. M.; Mohl, N. D. \& Spiller, H. Temporomandibular joint dysfunction masquerading as disease of ear, nose and throat. Trans. Am. Acad. Ophthalmol. Otolaryngol., 73(6):1208-17, 1969.

Bjorne, A. \& Agerberg, G. Craniomandibular disorders in patients with Meniere's disease: a controlled study. J. Orofac. Pain, 10(1):28-37, 1996.

Bjorne, A. \& Agerberg, G. Symptom relief after treatment of 
temporomandibular and cervical spine disorders in patients with Meniere's disease: A three year follow-up. Cranio, 21(1):5060, 2003.

Bjorne, A.; Berven, A. \& Agerberg, G. Cervical signs and symptoms in patients with Meniere's disease: a controlled study. Cranio, 16(3):194-202, 1998

Brookes, G. B.; Maw, A. R. \& Coleman, M. J. 'Costen's syndrome'-correlation or coincidence: a review of 45 patients with temporomandibular joint dysfunction, otalgia and other aural symptoms. Clin. Otolaryngol., 5(1):23-36, 1980.

Burch, J. G. The cranial attachment of the sphenomandibular (tympanomandibular) ligament. Anat. Rec., 156(4):433-8, 1966.

Burch, J. G. Activity of the accessory ligaments of the temporomandibular joint. J. Prosthet. Dent., 24(6):621-8, 1970.

Bush, F. M. Tinnitus and earache: Long term studies in 105 patients with temporomandibular disorders. J. Dent. Res., (special issue):185, 1986

Bush, F. M. Tinnitus and Otalgia in temporomandibular disorders. J. Prosthet. Dent., 58(4):495-8, 1987.

Campbell, C. D.; Loft, G. H.; Davis, H. \& Hart, D. L. TMJ symptoms and referred pain patterns. J. Prosthet. Dent., 47(4):430-3, 1982.

Chatellier, G.; Degoulet, P.; Devries, C.; Vu, H. A.; Plouin, P. F. \& Menard, J. Symptom prevalence in hypertensive patients. Eur. Heart J. 3 Suppl C:45-52, 1982.

Chole, R. A. \& Parker, W. S. Tinnitus and vertigo in patients with temporomandibular disorders. Arch. Otolaryngol. Head Neck Surg., 118(8):817-21, 1992.

Ciancaglini, R; Loreti, P. \& Radaelli, G. Ear, nose and throat symptoms in patients with TMD: The association of symptoms according to severity of arthropathy. J. Orofac. Pain, 8(3):2937, 1994.

Clark, G. T. \& Tsukiyama, Y. Sixty-eight years of experimental occlusal interference studies: What have we learned? $J$. Prosthet. Dent., 82:704-13, 1999.

Coderre, T. J.; Katz, J.; Vaccarino, A. L. \& Melzack, R. Contribution of central neuroplasticity to pathological pain: Review of clinical and experimental evidence. Pain, 52(3):259-285, 1993.

Coleman, R. D. Temporomandibular joint. Relations of the retrodiskal zone to Meckel's cartilage and lateral pterygoid muscle. J. Dent. Res., 49(3):626-30, 1970.

Conti, P. C.; dos Santos, C. N. \& Lauris, J. R. Interexaminer agreement for muscle palpation procedures: The efficacy of a calibration program. Cranio, 20(4):289-94, 2002.
Cooper, B. C.; Alleva, M.; Cooper, D. L. \& Lucente, F. E. Miofascial pain dysfunction: Analysis of 476 patients. Laryngoscope, 96(10):1099-2106, 1986.

Cooper, B. C. \& Cooper, D. L. Recognizing otolaryngologic symptoms in patients with temporomandibular disorders. Cranio, 11(4):260-7, 1993.

Correll, R. W.; Jensen, J. L.; Taylor, J. B. \& Rhyne, R. R. Mineralization of the stylohyoid-stylomandibular ligaments complex. Oral Surg. Oral Med. Oral Pathol., 8(4):286-91, 1979.

Costen, J. B. A syndrome of ear and sinus symptoms dependent upon disturbed function of the temporomandibular joint. Ann. Otol., 43(1):1-15, 1934.

Cowin, R. \& Bryner, P. Hearing loss otalgia and neck pain: A case report on long-term chiropractic care that helped to improve quality of life. Chriropract. J. Austral, 32(4):119-30, 2002.

Curtis, A. W. Miofascial pain-dysfunction syndrome: the role of non-masticatory muscles in 91 patients. Otolaryngol. Head Neck Surg., 88(4):361-7, 1980.

Dao, T. T. \& LeResche, L. Gender differences in pain. J. Orofac. Pain, 14(3):169-84, 2000.

Decker, J. D. Traumatic deafness as a result of retrusion of the condyles of the mandible. Ann. Otol. Rhinol. Laryngol., 34:519, 1925 .

Dolowitz, D. A.; Ward, J. W.; Fingerle, C. O. \& Smith C. C. The role of muscular incoordination in the pathogenesis of the temporomandibular joint syndrome. Laryngoscope, 74:790$801,1964$.

Dos Reis, A. C.; Hotta, T. H.; Ferreira-Jeronymo, R. R.; De Felicio, C. M. \& Ribeiro, R. F. Ear symptomatology and occlusal factors: A clinical report. J. Prosthet. Dent., 83(1): 21-4, 2000.

Dworkin, S. F. Perspectives on the interaction of biological, psychological and social factors in TMD. J. Am. Dent. Assoc., 125(7):856-63, 1994

Dworkin, S. F. \& Burgess, J. A. Orofacial pain of psychogenic origin: Currents concepts and classification. J. Am. Dent. Assoc., 115(4):565-71, 1987.

Dworkin, S. F. \& LeResche, L. Research diagnostic criteria for temporomandibular disorders: review, criteria, examinations and specifications, critique. J. Craniomandib. Disord. Facial Oral Pain, 6(4):301-55, 1992.

Edmeads, J. The cervical spine and headache. Neurology 38(12):1874-8, 1988

Eckerdal, O. The petrotynpanic Fissure: A link connecting the tympanic cavity and the temporomandibular joint. Cranio, 9(1):15-21, 1991. 
Ernest, E. A.; Martinez, M. E.; Rydzewski, D. B. \& Salter, E. G. Photomicrogrphic evidence of insertion tendonosis: The etiologic factor in pain for temporal tendonosis. J. Prosthet. Dent., 65(1):127-31, 1991.

Farella, M.; Michelotti, A.; Gargano, A.; Cimino, R. \& Ramaglia, L. Myofascial pain syndrome misdiagnosed as odontogenic pain: A case report. Cranio, 20(4):307-11, 2002.

Fernández, P.; Vasconsellos, E.; Okeson, J. P.; Bastos, R. L. \& Maia, M. L. The anatomical relationship between the position of the auriculotemporal nerve and mandibular condyle. Cranio, 21(3):165-71, 2003.

Fricton, J. R.; Kroening, R.; Haley, D. \& Siegert, R. Miofascial pain syndrome of the head and neck: a review of clinical characteristics of 164 patients. Oral Surg. Oral Med. Oral Pathol., 60:615-23, 1985.

Furstman, L. The early development of the human temporomandibular joint. Am. J. Orthodont., 49:672-82, 1963.

Gatchel, R. J.; Garofalo, J. P.; Ellis, E. \& Holt, C. Major psychological disorders in acute and chronic TMD: An initial examination. J. Am. Dent. Assoc., 127(9):136570, 1996.

Gelb, H. \& Arnold, G. E. Syndromes of the head and neck of dental origin. I. Pain caused by mandibular dysfunction. Arch. Otolaryngol., 70:681-91, 1959.

Gelb, H. \& Bernstein, I. M. Clinical evaluation of two hundred patients with temporomandibular joint syndrome. J. Prosthet. Dent., 49(2):234-43, 1983a.

Gelb, H. \& Bernstein, I. M. Comparison of three different populations with temporomandibular joint pain-dysfunction syndrome. Dent. Clin. North Am., 27(3):495-503, 1983 b.

Gelb, H.; Calderone, J. P.; Gross, S. M. \& Kantor, M. E. The role of the dentist and the otolaryngologist in evaluating temporomandibular joint syndromes. J. Prosthet. Dent., 18(5):497-503, 1967.

Gelb H. \& Tarte, J. A two-year dental clinical evaluation of 200 cases of chronic headache: the craniocervical-mandibular syndrome. J. Am. Dent. Assoc., 91(6):1230-6, 1975.

Gelb, H.; Gelb, M. L. \& Wagner, M. L. The relationship of tinnitus to craniocervical mandibular disorders. Cranio, 5(2):136-43, 1997.

Goodfriend, D. J. Symptomatology and treatment of abnormalities of the mandibular articulation. Dent. Cosmos, 75:844-52, 94760, 1933.

Gray, L. P. The relationship between the "superior constrictor swallow" clicking of the ears and ear disease. J. Laryngol. Otol., 97(12):1121-8, 1983.
Greene, C. S. The etiology of temporomandibular disorders: Implications for treatment. J. Orofac. Pain, 15(2):93-105, 2001.

Greene, C. S. \& Laskin, D. M. Temporomandibular disorders: Moving from a dentally based to a medically based model. $J$. Dental Res., 79(10):1736-9, 2000.

Greene, C. S. \& Marbach, J. J. Epidemiologic studies of mandibular dysfunction: A critical review. J. Prosthet. Dent. 48(2):184-90, 1982.

Hazell, J. W. Patterns of tinnitus: Medical audiological findings. $J$. Laryngol. Otol. Suppl., (4):39-47, 1981.

Hellstrom, F.; Thunberg, J.; Bergenheim, M.; Sjolander, P.; Pedersen, J. \& Johansson, H. Elevated intramuscular concentration of bradykinin in jaw muscle increases the fusimotor drive to neck muscles in the cat. J. Dent. Res. 79(10):1815-22, 2000.

Hertz, R. S. Pain resulting from elongated pterygoid hamulus: Report of case. J. Oral Surg., 26(3):209-10, 1968.

Holborow, C. Eustaquian tubal function: changes throughout childhood and neuro-muscular control. J. Laryngol. Otol., 89(1):47-55, 1975.

Hoshino, T. Surgical anatomy of the anterior epitympanic space. Arch. Otolaryngol. Head Neck Surg., 114(10):1143-5, 1988.

Hu, J. W.; Sessle, B. J.; Raboisson, P.; Dallel, R. \&Woda, A. Stimulation of craneofacial muscle afferents induces prolonged facilitatory effects in trigeminal nociceptive brain stem neurons. Pain, 48(1):53-60, 1992.

Hu, J. W.; Yu, X. M.; Vernon, H. \& Sessle, B. J. Excitatory effects on neck and jaw muscle activity of inflammatory irritant applied to cervical paraspinal tissues. Pain, 55(2):243-50, 1993.

Ioannides. C. A. \& Hoogland, G. A. The disco-malleolar ligament: A possible cause of subjective hearing loss in patients with TMJ. J. Maxillofac. Surg., 11(5):227-31, 1983.

Ishijima, K.; Sando, I.; Balaban, C. D.; Miura, M. \& Takasaki, K. Functional anatomy of levator veli palatini muscle and tensor veli palatini muscle in association with eustaquian tube cartilage. Ann. Otol. Rhinol. Laryngol., 111(6):530-6, 2002.

Johansson, A. S.; Isberg, A. \& Isacsson, G. A radiographic and histologic study of the topographic relations in the temporomandibular joint region. J. Oral Maxilofac. Surg., 48(9):953-61, 1990.

Kamerer, D. B. Electromyographic correlation of tensor tympani and tensor veli palatini muscles in man. Laryngoscope, 88(4):651-62, 1978.

Kato, T.; Rompre, R.; Montplaisir, J. Y.; Sessle, B. J. \& Lavigne, G. J. Sleep bruxism: an oromotor activity secondary to microarousal. J. Dent. Res., 80(10):1940-4, 2001. 
Keersmaekers, K.; De Boever, J. A. \& Van Den Verg, L. Otalgia in patients with temporomandibular joint disorders. J. Prosthet. Dent., 75(1):72-6, 1996.

Kelly, H. T.; Goodfriend, D. J. Vertigo attributable to dental and temporomandibular joint causes. J. Prosthet. Dent., 1:159-73, 1964.

Kierner, A. C.; Mayer, R. \& Kirschhofer, K. Do the tensor tympani and tensor veli palatini muscles of man form a functional unit? A histochemical investigation of their putative connections. Hear Res, 165(1-2):48-52, 2002.

Kim, H. S.; Chung, S. C.; Kim, Y. K. \& Lee, S. W. Pain-pressure threshold in the head and neck region of episodic tension-type headaches patients. J. Orofac. Pain, 9(4):357-64, 1995.

Kinney, R. K.; Gatchel, R. J.; Ellis, E. \& Holt, C. Major psychological disorders in chronic TMD patients: Implications for successful management. J. Am. Dent. Assoc., 123(10):4954,1992

Kisnisci, R.; Onder, E.; Tuz, H. Prevalence of Otologic Complaints in Temporomandibular Disorder Patients. Int. J. Oral \& Maxillofacial Surgery, 28(1):101-2, 1999.

Klausner, J. J. Epidemiologic of chronic facial pain: diagnostic usefulness in patient care. J. Am. Dent. Assoc., 125(12):160411,1994

Klockhoff, I. \& Anderson, H. Reflex activity in the tensor tympani muscle recorded in man. Acta Oto-laryngol., 51:184-8, 1960.

Koelbaek Johansen, M.; Graven-Nielsen, T.; Schou Olesen, A. \& Arendt-Nielsen, L. Generalised muscle hyperalgesia in chronic whiplash syndrome. Pain, 83(2):229-34, 1999.

Komori, E.; Sugisaki, M.; Tanabe, H. \& Katoh, S. Discomalleolar ligament in the adult human. Cranio 4(4):300-5, 1986.

Kopp, S. Neuroendocrine, immune, and local responses related to temporomandibular disorders. J. Orofac. Pain., 15(1):9-28, 2001.

Kopstein, E. Hyoid syndrome. Archives of Otolaryngol., 101(8):484-5, 1975.

Koskinen, J.; Paavolainen, M.; Raivio, M. \& Roschier, J. Otological manifestations in temporomandibular joint dysfunction. J. Oral Rehabil., 7(3):249-54, 1980.

Kunachak, S. Anterior cervical pain syndromes: hyoid, thyroid, and crycoid cartilages syndromes and their treatment with triaminalone acetamide. J. Laryngol. Otol., 109(1):49-52, 1995.

Kuttila, S. J.; Kuttila, M. H.; Le Bell, Y.; Alanen, P. \& Jouko, S. Aural Symptoms and Signs of Temporomandibular Disorder in Association with Treatment Need and Visits to Physician. Laryngoscope, 109(10):1669-73, 1999.
Kuttila, S. J.; Kuttila, M. H.; Niemi, P. M.; Le Bell, Y. B.; Alanen, P. J. \& Suonpaa, J. T. Secundary otalgy in adult population. Archives Otolaryngologic Head Neck Surgery 127(4):401-5, 2001.

Lam, D. K. Lawrence HP, Tenenbaum HC. Aural symptoms in temporomandibular disorder patients attending a orofacial pain unit. J. Orofac. Pain,15(2):146-57, 2001.

Leuwer, R.; Schubert, R.; Kucinski, T.; Liebig, T. \& Maier, H. The muscular compliance of the auditory tube: a model-based survey. Laryngoscope, 112(10):1791-5, 2002.

Leighty, S. M.; Spach, D. H.; Myall, R. T. W. \& Burns, J. L. Septic arthritis of the temporomandibular joint: review of the literature and report of two cases in children. Int. J. Oral Maxillofac. Surg., 22(5):292-7, 1993.

Levine, R. A. Somatic (craniocervical) tinnitus and the dorsal cochlear nucleus hypothesis. Am. J. Otolaryngol., 20(6):35162,1999

Lipton, J. A.; Ship, J. A. \& Larach-Robinson, D. Estimated prevalence and distribution of reported orofacial pain in the United States. J. Am. Dent. Assoc., 124(10):115-21, 1993.

Lockwood, A. H.; Salvi, R. J. \& Burkard, R. F. Tinnitus. New Engl. J. Med., 347(12):904-10, 2002.

Lockwood, A. H.; Salvi, R. J.; Coad, M. L.; Towsley, M. L.; Wack, D. S. \& Murphy, B. W. The functional neuroanatomy of tinnitus. Evidence of limbic system links and neural plasticity. Neurology, 50(1):114-20, 1998.

Loughner, B. A.; Larkin, L. H. \& Mahan, P. E. Discomalleolar and anterior malleolar ligaments: Possible causes of middle ear damage during temporomandibular joint surgery. Oral Surg. Oral Med. Oral Pathol., 68(1):14-22, 1989.

Loughner, B. A.; Larkin, L. H.; Mahan, P. E. Nerve entrapment in the lateral pterygoid muscle. Oral Surg. Oral Med.Oral Pathol., 69(3):299-306, 1990

Lund, J. P.; Donga, R.; Widmer, C. G. \& Stohler, C. S. The pain adaptations model: A discussion of the relationship between chronic musculoskeletal pain and motor activity. Can. J. Physiol. Pharmacol., 69(5):683-94, 1991.

Lund, J. P.; Lavigne, G. J.; Dubner, R. \& Sessle, B. J. Orofacial pain. From basic science to clinical management. Quintessence Publishing Co, Inc. Chicago, 2001.

Marasa, F. K. \& Ham, B. D. Case reports involving the treatment of children with chronic otitis media with effusion via craniomandibular methods. Cranio, 6(3):256-70, 1988.

McDonnell, J. P.; Needleman, H. L.; Charchut, S.; Allred, E. N.; Roberson, D. W.; Kenna, M. A. \& Jones, D. The Relationship Between Dental Overbite and Eustachian Tube Dysfunction. Laryngoscope, 111:310-16, 2001. 
McNeill, C. History and evolution of TMD concepts. Oral Surg. Oral Med. Oral Pathol. Oral Radiol. Endod., 83(1):51-60, 1997.

McNeill C, ed. Craniomandibular disorders: guidelines for Evaluation, Diagnosis, and Management. Chicago, Quintessence Publ Co, 1990.

McNeill C, ed. Temporomandibular Disorders - Guidelines for classification, assessment, and management. Chicago, Quintessence Publishing Co, 1993.

Mense, S. Nociception form skeletal muscle in relation to clinical muscle pain. Pain, 54(3):241-89, 1993.

Mérida-Velasco, J. R.; Rodriguez-Vazquez, J. F.; Merida-Velasco, J. A. \& Jimenez-Collado, J. The vascular relationship between the temporomandibular joint and the middle ear in the human fetus. J. Oral Maxillofac. Surg., 57(2):146-53, 1999.

Merida Velasco, J. R.; Rodriguez Vazquez, J. F. \& Jimenez, Collado J. Anterior tympanic artery: course, ramification and relationship with the temporomandibular joint. Acta Anat., 158(3):222-6, 1997.

Miller, D. A. \& Wyrwa, E. B. Ear pain: A dental dilema. Compendium, 13(8):676-84, 1992.

Misurya, V. K. Functional anatomy of tensor palati and levator palati muscles. Arch. Otolaryngol., 102(5):265-70, 1976a.

Misurya, V. K. Tensor tympani, a 'tuner' of tensor palati muscle. Acta Otolaryngol., 82(5-6):410-4, 1976b.

Moller, A. R.; Moller, M. B. \& Yokota, M. Some forms of tinnitus may involve the extralemniscal auditory pathway. Laryngoscope, 102:1165-71, 1992.

Molin, C. From bite to mind: TMD--a personal and literature review. Int. J. Prosthodont., 12(3):279-88, 1999.

Morgan, D. H. Tinnitus of TMJ: A preliminary report. Cranio, 10(2):124-9, 1992.

Morgan, D. H.; Goode, R. L.; Christiansen, R. L. \& Tiner, L. W. The TMJ-Ear Connection. Cranio, 13(1):42-3, 1995.

Moses, J. J.; Langue, C. R. \& Arredondo, A. Septic arthritis of the temporomandibular joint after the removal of a third molars. J. Oral Maxillofac. Surg., 56(4):510-2, 1998.

Myers, L. J. Possible inflammatory pathways relating temporomandibular joint dysfunction to otic symptoms. Cranio, 6(1):64-70, 1988.

Myrhaug, H. The incidence of the ear symptoms in cases of malocclusion and temporomandibular joint disturbances. $B r$. J. Oral Maxillofac. Surg., 2:28-32, 1964,
National Institute of Health Technology Assessment Conference on Management of Temporomandibular Disorders; 1996 Apr 29-May 1; Bethesda (MD).

Ogutcen-Toller, M. \& Juniper, R. P. Audiological evaluation of the aural symptoms in temporomandibular joint dysfunction. J. Craniomaxillofac. Surg., 21(1):2-8, 1993.

Ogutcen-Toller, M. The morphogenesis of the human discomalleolar and sphenomandibular ligaments. J. Craniomaxillofac. Surg., 23(1):42-6, 1995 .

Ohta, Y.; Suwa, F. M.; Yang, L.; Wang, M. \& Wang, H. Development and histology of fibrous architecture of the fetal temporomandibular joint. Okajimas Folia Anat. Jpn. 70(1):1$5,1993$.

Okeson, J. P. ed. Management of temporomandibular disorders and occlusion. 4. ed. St. Louis, Mosby, 1998. pp. 149-77.

Okeson, J. P. Ed. Orofacial pain. Guidelines for assessment, diagnosis, and management. The American Academy of Orofacial Pain. Chicago, Quintessence Publishing Co., 1996.

Parker, W. S. \& Chole, R. A. Tinnitus, vertigo and temporomandibular disorders. Am. J. Orthod. Dentofacial Orthop., 107(2):153-8, 1995.

Pergamalian, A.; Thomas, R.; Hussein, Z. \& Greco, C. The association between wear facets, bruxism, and severity of facial pain in patients with temporomandibular disorders. $J$. Prosthetic Dentistry, 90(2):194-200, 2003.

Perry, H. T.; Xu, Y. \& Forbes, D. P. The embryology of the temporomandibular joint. Cranio, 3(2):125-32, 1985.

Peterson, J. N.; Schames, J.; Schames, M. \& King, E. Sphenopalatine ganglion block: A safe and easy method for the management of orofacial pain. Cranio, 13(3):177-81, 1995.

Pinto, O. F. A new structure related to the temporomandibular joint and middle ear. J. Prosthet. Dent., 12(1):95-103, 1962.

Prades, J. M.; Dumollard, J. M.; Calloc'h, F.; Merzougui, N.; Veyret, C. \& Martin, C. Descriptive anatomy of the human auditory tube. Surg. Radiol. Anat., 20(5):335-40, 1998.

Principato, J. J. \& Barwell, D. R. Biofeedback training and relaxation exercises for treatment of temporomandibular joint dysfunction. Otolaryngology. 86(5):ORL-766-9, 1978.

Proctor, B. Embryology and anatomy of the Eustaquian tube. Arch. Otolaryngol., 86(5):503-14, 1967.

Raustia, A. M.; Oikarinen, K. S.; Luotonen, J.; Salo, T. \& Pyhtinen, J. Parotid gland carcinoma simulating signs and symptoms of craniomandibular disorders- A case report. Cranio, 11(2):1536, 1993. 
Rees, L. A. The structure and function of the mandibular joint. $\mathrm{Br}$ Dent. J., 96:125-33, 1954.

Regev, E.; Koplewitz, B.; Nitzan, D. \& Bar-Ziv, J. Ankylosis of the temporomandibular joint as a sequela of septic arthritis and neonatal sepsis. Pediatric. Infectious Disease J. 22(1):99-101, 2003.

Ren, Y. F. \& Isberg, A. Tinnitus in patients with temporomandibular joint internal derangement. Cranio, 13(2):75-80. 1995.

Rodriguez Vazquez, J. F.; Merida Velasco, J. R. \& Jimenez Collado, J. A study of the os goniale in man. Acta Anat., 142:188-92, 1991.

Rodriguez Vazquez, J. F.; Merida Velasco, J. R. \& Jimenez Collado, J. Relationships between the temporomandibular joint and the middle ear in human fetuses. J. Dent. Res., 72(1):62-6, 1993.

Rodriguez Vazquez, J. F.; Merida Velasco, J. R.; Jimenez Collado, J. Development of the human sphenomandibular ligament. Anat. Rec., 233(3):453-60, 1992.

Rodríguez-Velasquez, J. F.; Merida-Velasco, J. R.; Merida-Velasco, J. A. \& Jimenez-Collado, J. Anatomical considerations on the discomalleolar ligament. J. Anat., 192(Pt 4):617-21, 1998.

Rood, S. R. The morphology of muscle tensor veli palatini in the five month human fetus. Am. J. Anat., 138(2):191-5, 1973.

Rood, S. R. \& Doyle, W. J. Morphology of the tensor veli palatiny, tensor tympani and dilatator tubae muscles. Ann. Otol. Rhinol. Laryngol., 87(2 Pt 1):202-10, 1978.

Ross, M. A. Functional anatomy of the tensor palati. Arch Otolaryngol., 93(1):1-3, 1971

Rubinstein, B. Tinnitus and craniomandibular disorders-- Is there a link? Swed. Dent. J. Suppl., 95:1-46, 1993.

Rubinstein, B. \& Carlsson, G. E. Effects of Stomatognathic treatment on tinnitus: A retrospective study. Cranio, 5(3):254-9, 1987.

Rubinstein, B.; Axelsson, A. \& Carlsson, G. E. Prevalence of signs and symptoms of craniomandibular disorders in tinnitus patients. J. Craniomandib. Dis. Facial Oral Pain, 4(3):186-92, 1990.

Sadler, T. W. Langman Embriología Médica. 7. ed. Médica Panamericana, México, 1998. Cap. 16 -17.

Salen, B. \& Zakrisson, J. E. Electromyogram of the tensor tympani muscle in man during swallowing. Acta Otolaryngol., 85(56):453-5, 1978 .

Salvinelli, F.; Casale, M.; Paparo, F.; Persico, M. \& Zini, C. Subjective tinnitus, ztemporomandibular joint dysfunction, and serotonin modulation of neural plasticity: causal or casual triad? Medical Hypotheses, 61(4):446-8, 2003.
Santander, H.; Millares, R.; Jimenez, A.; Zuñiga, C.; Rocabado, M. \& Moya, H. Influence of stabilization occlusal splint on craniocervical relationships. Part II: Electromyographic analysis. Cranio, 12(4):227-33, 1994.

Schames, J.; Schames, M.; King, E.; Ulansey, S.; Boyd, J. \& Schames, E. Trigeminal Pharyngioplasty: Treatment of the forgotten accessory muscles of mastication which are associated with orofacial pain and ear symptomatology. American Journal of Pain Management 2002;12:102-12.

Schmidt, B. L.; Pogrel, M. A.; Necoechea, M. \& Kearns, G. The distribution of the auriculotemporal nerve around the temporomandibular joint. Oral Maxillofa. Surg., 86(2):165-8, 1998.

Shankland, W. E. Ernest syndrome as a consequence of stylomandibular ligament injury: A report of 68 patients. $J$. Prosthet. Dent., 157(4):501-6, 1987.

Shore, S. E.; Vass, Z.; Wys, N. L. \& Altschuler, R. A. Trigeminal ganglion innervates the auditory brainstem. J. Comp. Neurology, $10 ; 419(3): 271-85,2000$

Sessle, B. J. Acute and chronic craniofacial pain: Brain stem mechanism of nociceptive transmission and neuroplasticity and their clinical correlates. Crit. Rev. Oral Biol. Med. 11(1):57-91, 2000 .

Sessle, B. J.; Bryant, P. S. \& Dionne, R. N. editors. TMD and related pain conditions. In: Fields HL, editor. Progress in pain research. Seattle, IASP Press, 1995. V. 4.

Shapiro, H. H. \& Truex, R. C. The temporomandibular joint and the auditory function. J. Am. Dent. Assoc., 30:1147-68, 1943.

Skeppar, J. \& Nilner, M. Treatment of craniomandibular disorders in children and young adults. J. Orofac. Pain., 7(4):362-9, 1993.

Sobhy, O. A.; Koutb, A. R.; Abdel-Baki, F. A.; Ali, T. M.; El Raffa, I. Z. \& Khater, A. H. Evaluation of aural manifestations in temporo-mandibular joint dysfunction. Clin. Otolaryngol., 29:382-5, 2004

Solberg, W. K.; Woo, M. W. \& Houston, J. B. Prevalence of mandibular dysfunction in young adult. J. Am. Dent. Assoc. 98(1):25-34, 1979.

Spauwen, P. H.; Hillen, B.; Lommen, E. \& Otten, E. Three-dimensional computer reconstruction of the eustachian tube and paratubal muscles. Cleft Palate Craniofac, J., 18(2):217-9, 1991.

Svensson, P.; Arendt-Nielsen, L. \& Houe L. Sensory-motor interactions of human experimental unilateral jaw muscle pain: A quantitative analysis. Pain, 64(2):241-9, 1996.

Svensson, P.; Graven-Nielsen, T. \& Arendt-Nielsen, L. Mechanical hyperesthesia of human facial skin induced by tonic painful stimulation of jaw muscles. Pain, 74(1):93-100, 1998. 
Svensson, P. \& Graven-Nielsen, T. Craniofacial muscle pain: Review of mechanisms and clinical manifestations. J. Orofac. Pain, 15(2):117-45, 2001.

Su, C. Y.; Hsu, S. P. \& Chee, E. C.Electromiographic recording of tensor and levator veli palatini muscle: a modified transnasal insertion method. Laryngoscope, 103(41):459-62, 1993.

Swarts, J. D. \& Rood, S. R. The morphometry and three-dimensional structure of the adult eustachian tube: implications for function. Cleft Palate J., 27(4):374-81, 1990.

Thilander, B.; Carlsson, G. E. \& Ingervall, B. Postnatal development of the human temporomandibular joint. I. A histological study. Acta Odontol Scand., 34(2):117-26, 1976.

Travell, J. G. \& Simons, D. G. Dolor y disfuncion miofascial. El manual de los puntos gatillo, Mitad superior del cuerpo. 2. ed. Panamericana, México, 2002. V. 1. pp 419,455,476.

Tuz, H. H.; Onder, E. M. \& Kisnisci, R. S. Prevalence of otologic complaints in patients with temporomandibular disorder. Am. J. Orthod. Dentofacial Orthop., 123:620-3, 2003.

Vass, Z.; Shore, S. E.; Nuttall, A. L.; Miller, J. M. Direct evidence of trigeminal innervation of the cochlear blood vessels. Neuroscience, 84(2):559-67, 1998.

Vergara, R. M. Audición y sordera. Lerner Ltda, DRG 2000 Ltda. Colombia, 1996. Cap 9.

Vernon, J.; Griest, S. \& Press, L. Attributes of tinnitus that may predict temporomandibular joint dysfunction. Cranio 10(4):282-7, 1992.

Virtanen, H. Objective tubal tinnitus: a report of two cases. $J$. Laryngol. Otol., 97(9):857-62, 1983.

Wall, P. D. The gate control theory of pain mechanisms: A reexamination and restatement. Brain, 101(1):1-18, 1978.

Wedel, A. \& Carlsson, G. E. A four-year follow-up, by means of a questionnaire, of patients with functional disturbances of the masticatory system. J. Oral Rehabil., 13(2):105-13, 1986.

Weiss, N. S. Relation of high blood pressure to headache, epistaxis, and selected other symptoms. The United States Health Examination Survey of Adults. N. Engl. J. Med., 287(13):6313, 1972.

Whyte, J. R.; González, L.; Cisneros, A. I.; Yus, C.; Torres, A. \& Sarta, R. Fetal Development of the Human Tympanic Ossicular Chain Articulations. Cells Tissues Organs, 171:241-, 2002.

Williams, P. L.; Warwick, R.; Dyson, M. \& Bannister, L. H. Gray's Anatomy. 37. ed. Edinburgh, Scotland, Churchill Livingston. 1989. pp 1113, 1227.

Williamson, E. H. Interrelationship of internal derangements of the temporomandibular joint, headache, vertigo, and tinnitus: a survey of 25 patients. Cranio, 8(4):301-6, 1990.

Woolf, C. J. \& Thompson, S. W. The induction and maintenance of central sensitizations dependent on N-methyl-D-aspartic acid receptor activation: Implications for the treatment of post-injury pain hypersensitivity. Pain, 44(3):293-9, 1991.

Wong, G. B.; Weinberg, S. \& Symington, J. M. Morphology of the developing articular disc of the human temporomandibular joint. J. Oral Maxillofac. Surg., 43(8):565-9, 1985.

Wright, E. F. \& Syms, C. A. \& Bifano, S. L. Tinnitus, dizziness, and nonotologic otalgia improvement through temporomandibular disorder therapy. Mil. Med., 165(10):7336,2000 .

Yamamoto, E.; Nishimura, H. \& Iwanaga, M. Tinnitus and/or hearing loss elicited by facial mimetic movement. Laryngoscope, 95(8):966-70, 1985.

Young, E. D.; Nelken, I. \& Conley, R. A. Somatosensory effects on neurons in dorsal cochlear nucleus. J. Neurophysiol., 73(2):74365, 1995.

Young, M. W. Fluid channels in the temporal bone. Anat. Rec., 112:438-9, 1952.

Youniss, S. The relationship between craniomandibular disorders and otitis media in children. Cranio, 9(2):169-73, 1991.

Yuodelis, R. A. The morphogenesis of the human temporomandibular joint and associated structures. J. Den.t Res., 45:182-91, 1996.

Zipfel, T. E.; Kaza, S. R. \& Greene, J. S. Middle-ear myoclonus. J. Laryngol. Otol., 114(3):207-9, 2000.

Correspondence to:

Prof. Dr. Luis Miguel Ramirez Aristeguieta

Department of Basic Sciences

Faculty of Medicine

Universidad Industrial de Santander (UIS)

Bucaramanga

Calle 45 № 0 33-17. 702B.

Bucaramanga

$\operatorname{COLOMBIA~}$

Email:Imra3@yahoo.com

Received: 18-01-2005

Accepted: 22-04-2005 